\title{
A CORRUPÇÃO E OS CONTROLES INTERNOS DO ESTADO
}

\author{
Marcelo Araújo \\ Oscar Adolfo Sanchez
}

\section{Introdução}

Um dos principais desafios dos Estados Modernos é desenvolver capacidade de resolver uma questão básica: o problema do controle exercido pelos políticos eleitos sobre a burocracia, dada a inevitabilidade da delegação de responsabilidades dos primeiros aos segundos (Niskanen, 1971; Przeworski, 1996).

Segundo Weber, numa democracia representativa, os políticos eleitos são detentores de legitimidade e responsabilidade política. Cabe a eles, por meio dos partidos, a formulação de programas políticos a serem julgados pelos eleitores. Com o advento da burocracia como forma de dominação racional/legal, Weber percebeu o risco de a burocracia estatal avançar em suas atribuições e passar a formular políticas, dado que dispõe de conhecimento técnico necessário para tanto. Todavia, por mais que a formulação de políticas necessite de conhecimento técnico, a burocracia não é apta a tomar esta ou aquela decisão, pois lhe falta legitimidade. É uma questão de accountability política, já que os burocratas não são eleitos.

Segundo a Teoria de Agência, o problema na relação governo/burocracia reside na assimetria de informação, ou 
seja, no fato de duas partes que se relacionam não deterem o mesmo conhecimento, colocando uma das partes - quem delega responsabilidades - em desvantagem no relacionamento com a outra. Aproveitar essa assimetria de informação pode levar a burocracia a buscar interesses distintos aos dos políticos eleitos. Isto é, pode haver o falseamento das metas estabelecidas pelo poder político. E um exemplo disso é dado pela corrupção burocrática.

A corrupção, em qualquer de suas manifestações, representa um ônus insustentável para qualquer sociedade, principalmente para as que são permeadas por grandes desigualdades sociais, como são as Latino-Americanas. Sem dúvida é uma das mais perversas categorias criminosas, pois mina a capacidade dos Estados em prover serviços essenciais para a população. Ela retarda a ruptura dos ciclos de pobreza, da mesma forma que compromete a consolidação e o avanço da democracia. Pode acabar por deslegitimar ou minar a credibilidade de um regime. Como argumenta Adam Przeworski (1997, p. 37), ela faz parte do menu que torna um determinado regime indesejável. Em outras palavras, converte-o numa alternativa não preferida pela população.

Dado que para o fenômeno da corrupção soluções universais não existem, apenas estudos aprofundados sobre o funcionamento das instâncias de regulação e controle podem indicar os caminhos para enfrentar a corrupção de maneira efetiva (Speck, 2000, p. 09). E esse é o objetivo deste texto: estudar os mecanismos de controle sobre a corrupção administrativo/burocrática a partir dos conceitos oferecidos pela Teoria de Agência. Procura-se com este estudo contribuir para a reflexão sobre o problema da corrupção e colaborar na produção de conhecimento sobre as áreas e instituiçõeschave no aparelho estatal que possam oferecer soluções para o problema.

O trabalho está organizado da seguinte forma: primeiramente trata-se de argumentar sobre a importância da uti- 
lização do individualismo metodológico para o estudo dos controles sobre a corrupção na Administração Pública, através da formulação do modelo comportamental dos agentes. Em seguida, é estabelecido o problema dos controles sobre a burocracia como conseqüência de uma das principais características do poder burocrático, qual seja, do controle da informação. Neste sentido, as instituições serão consideradas fundamentais para a definição das estratégias dos atores, pois representam constrangimentos às suas escolhas. Isto é, através de arranjos institucionais específicos seria possível minimizar o problema derivado da assimetria de informação presente nas relações entre o governo e a burocracia.

O tratamento do problema a partir dos conceitos desenvolvidos pela Teoria da Agência nos permitirá avançar em dois aspectos importantes: a) em uma redefinição do conceito de Controle Interno; e b) apresentação dos parâmetros necessários à organização de um sistema de Controle Interno. Finalmente, serão analisadas as condições que permitem a construção de arranjos institucionais de Controle Interno e a interconexão destes controles com os controles democráticos do Estado e a transparência administrativa.

\section{Os Controles Internos}

O tratamento da corrupção deve partir de algumas considerações prévias. Existe uma falta de consenso quanto a uma conceituação geral do que seja corrupção. Uma das dificuldades é decorrente do fato de que qualquer definição de corrupção é condicionada pelo conjunto de instituições e valores de uma determinada sociedade em seu contexto histórico. Neste sentido, para delimitar historicamente o conceito, estaremos nos referindo a um certo tipo de relação social que acontece em um Estado que Robert Dahl (1997) definiu como Poliarquia. Isto implica a existência de um marco institucional definidor do que é público e do que é privado e do que é o uso ilegal da coisa pública. Um Estado 
de Direito com uma burocracia profissional instalada ou em processo de instalação.

Dado o marco histórico, definimos corrupção como $o$ uso do poder de um cargo público, à margem da lei, para a obtenção de ganhos privados. É certo que qualquer que seja a definição dada à corrupção ela pode ser questionada, de uma forma ou outra. O importante nessa definição mínima é a ênfase dada à utilização de um determinado poder do Estado de forma ilegal.

A preocupação com a limitação do poder do Estado não é nova. Desde Maquiavel a reserva quanto à solidariedade entre os homens encontra-se em diversas correntes de pensamento. Mas foi James Madison que melhor expressou a preocupação republicana de como controlar os homens detentores do poder do Estado. Assim, tornou-se um tema recorrente o estudo e a compreensão desses controles. Dentro dessa perspectiva, mostraremos a seguir os tipos de controle sobre o poder do Estado democrático/representativo, de forma geral, e os controles institucionais sobre a burocracia, de forma particular. Como este trabalho visa ao estudo dos mecanismos que previnam as práticas de corrupção administrativo-burocrática, nos deteremos num tipo específico de controle: o controle interno da administração pública.

Comecemos a exposição definindo alguns conceitos. De acordo com a legislação brasileira, em um sentido amplo, governo é a resultante da interação dos três Poderes do Estado: Executivo, Legislativo e Judiciário. Nas palavras de Hely Lopes Meirelles: "É a expressão política do comando, da fixação de objetivos do Estado e de manutenção da ordem jurídica." (Meirelles, 2000, p. 59.) Para a consecução dos objetivos do governo existe um conjunto de órgãos e entidades chamados, em sentido formal, de Administração Pública.

Todas as pessoas físicas incumbidas do exercício de alguma função estatal são chamadas de agentes públicos. Estes podem ser agentes políticos ou agentes administrati- 
vos. Os agentes políticos são os componentes do governo nos seus primeiros escalões e atuam com plena liberdade funcional. São as autoridades públicas supremas do governo e da Administração. Já os agentes administrativos são todos aqueles que se vinculam ao Estado por relações profissionais, sujeitos a hierarquia funcional.

Para o exercício de suas funções, os agentes administrativos dispõem de poder administrativo, cujas principais características são o de ser vinculado - preso ao enunciado da lei - e ao mesmo tempo discricionário - ou seja, pode fazer escolhas dentro do que permite a lei. Tais poderes são instrumentos de trabalho, adequados à realização das tarefas administrativas. São poderes instrumentais, diversamente dos poderes políticos. Estes são estruturais e orgânicos, porque compõem a estrutura do Estado e integram a organização constitucional (Meirelles, 2000, p. 107).

Os poderes administrativos são extrínsecos, conferidos aos agentes por meio do Direito Positivo. Mas os agentes administrativos dispõem também de um poder intrínseco. Por constituírem um grupo especializado e possuir alta capacidade organizacional, os burocratas detêm certa quantidade e qualidade de informação que os coloca em posição de vantagem em relação aos agentes políticos. A informação, a competência técnica e o conhecimento específico são os fundamentos desse poder, que será aqui chamado de poder burocrático.

Os controles sobre esse poder administrativo/burocrático inserem-se em um contexto maior: o controle do poder do Estado. Institucionalmente, existem três principais formas de impor limites à ação dos agentes do Estado. A primeira delas é constituída pelos "freios sociais".

Os "freios sociais" à ação dos agentes do Estado são constituídos pelos chamados mecanismos de controle verticais, isto é, da sociedade em relação ao Estado. Estes mecanismos aqui serão chamados de controles sociais. A principal 
forma de controle vertical é a dimensão eleitoral, ou seja, premiar ou punir um governante nas eleições. Essa dimensão requer a vigência dos mecanismos que caracterizam uma Poliarquia como definida por Robert Dahl (1997): liberdade de opinião, de associação e de imprensa, entre outros. Além disso, o controle vertical se manifesta por meio de "ações realizadas, individualmente ou por algum tipo de ação organizada e/ou coletiva, com referência àqueles que ocupam posições em instituições do Estado, eleitos ou não" (O’Donnell, 1998, p. 31), isto implica a existência de diversos mecanismos que permitam aos cidadãos tanto reivindicar demandas diversas como denunciar certos atos dos agentes públicos.

A segunda principal forma de impor limites à ação dos agentes do Estado se dá pelos mecanismos de limitação e controle na própria arquitetura do Estado, também chamados de "mecanismos de controle horizontais". Envolvem a existência de instituições, agências e órgãos estatais detentores de poder, legal e de fato, de realizar ações que vão desde a supervisão de rotina até sanções legais contra atos delituosos de seus congêneres do Estado. Este sistema não se limita às instituições mais importantes do sistema político, como o controle mútuo entre o Legislativo, o Executivo e o Judiciário, mas também outras instituições intermediárias. No Brasil, as mais importantes são o Ministério Público e os Tribunais de Contas, instituições que têm alto grau de autonomia em relação à própria organização institucional e à interpretação da tarefa de controle (Speck, 2000, p. 23).

Existe ainda um terceiro tipo de controle institucional dentro da estrutura do Estado que, diferentemente dos mecanismos baseados nos princípios de controle vertical e horizontal, acima citados, é subordinado ao princípio hierárquico: é o chamado "controle administrativo". Esse controle é definido por Hely Meirelles da seguinte forma: 
“... é todo aquele [controle] que o Executivo e os órgãos de administração dos demais Poderes exercem sobre suas próprias atividades, visando mantê-las dentro da lei, segundo as necessidades do serviço e as exigências técnicas e econômicas de sua realização, pelo que é um controle de legalidade e de mérito." (Meirelles, 2000, p. 614.)

Roberto Piscitelli (1995, p. 74) nos esclarece de que forma se daria esse controle da legalidade e de mérito. Segundo este autor são quatro os principais objetivos dos mecanismos de controle interno: a) a revisão e/ou verificação das operações sob os aspectos eminentemente contábeis, formais e legais; b) a eficiência, que concerne aos meios empregados, aos recursos utilizados para a consecução dos objetivos; c) a eficácia, a verificação do produto, dos programas, dos fins perseguidos; e, d) a avaliação dos resultados.

Segundo Meirelles (2000) "o controle administrativo deriva do poder/dever de autotutela que a Administração tem sobre seus próprios atos e agentes. Esse controle é normalmente exercido pelos órgãos superiores sobre os inferiores [...] pelo quê se caracteriza como controle interno, pois o externo é sempre atribuído a órgão estranho ao Executivo" (idem, p. 615, itálico nosso). Desta forma, chegamos à definição de controle interno dada por Meirelles:

“...[é] todo o [controle] realizado pela entidade ou órgão responsável pela atividade no âmbito da própria administração. Assim qualquer controle efetuado pelo Executivo sobre seus serviços ou agentes é considerado interno, como interno será também o controle do Legislativo ou Judiciário por seus órgãos de administração, sobre seu pessoal e os atos administrativos que pratique." (idem, p. 612.) 
Como podemos perceber, Meireles define o controle interno e o controle administrativo praticamente da mesma forma. O que é necessário enfatizar para o interesse deste trabalho é que este tipo de controle consiste em um autocontrole, pois é exercido pelos diferentes Poderes ou Agências sobre seus próprios atos e agentes, por meio do princípio hierárquico.

No entanto, existe um problema em se assumir essas definições, da forma como são dadas por Meirelles, pois um aspecto importante escapa à discussão puramente administrativa: é o que se refere ao tipo de responsabilidade dos agentes dentro da estrutura hierárquica da Administração Pública. Neste sentido, Weber, em seus estudos sobre burocracia, estabeleceu uma distinção nítida entre os agentes administrativos e o grupo que o emprega. O primeiro é identificado por algumas características comuns básicas que são: hierarquia, continuidade, impessoalidade e competência. O corpo diretivo, por sua vez, é geralmente eleito ou nomeado por agentes eleitos e tem como função formular de modo amplo a política e as diretrizes da organização e prover os fundos necessários. Sua responsabilidade é exterior à organização. Os membros da burocracia, pelo contrário, são responsáveis perante o corpo diretivo pela execução da sua política e pela administração de seus fundos. Como assinala Beetham (1988, p. 26): "Embora esta diferenciação possa por vezes ser confusa na prática, é vital em princípio." Isto significa que embora todo agente público tenha responsabilidade administrativa, apenas a cúpula de uma organização pública tem responsabilidade política. É ela que deve responder pelo conjunto da organização aos controles horizontais e aos controles sociais. Esta distinção, como veremos ao longo do trabalho, será fundamental para estabelecer uma diferenciação entre os controles administrativos e os controles exercidos pela cúpula política/burocrática.

A literatura existente sobre os controles internos no Brasil, aponta que tais controles historicamente atenderam 
apenas ao primeiro dos itens citados por Piscitelli, ou seja, são controles essencialmente formalistas: apenas verificam se os gastos são feitos de acordo com o processo contábil e legal correspondente ${ }^{1}$. No entanto, esta fragilidade desses controles não pode ser creditada apenas à falta de vontade das cúpulas dirigentes. É necessário levarmos em conta as dificuldades de se implementar reformas que levem a um aumento do poder de controle derivados do problema quase insolúvel da assimetria de informação entre controlador e controlado. Ou seja, entre "querer" controlar e "poder" controlar existe uma diferença nítida².

O ponto a se destacar é que o controle sobre a burocracia estatal não é um fato dado. A fragilidade dos controles sobre a burocracia no Brasil foi tida (e em grande medida ainda é) como uma das causas da dificuldade do Estado em modernizar-se, o que, conseqüentemente, gera enormes dificuldades para o controle social sobre o Estado ${ }^{3}$. Em síntese, a construção de mecanismos que tornem viável esse tipo de controle representou sempre um problema para a elite vitoriosa eleitoralmente, possuidora de legitimidade e responsabilidade política.

\section{A Questão Burocrática}

Em virtude da crescente complexidade das estruturas Estatais e da diminuição da eficiência da administração pública, a partir da crise fiscal dos Estados Nacionais da década de 1970, diversas correntes de pensamento propuseram reformas administrativas que de uma maneira ou de outra

1. Ver Cretella Júnior (1985); Campos (1990); Reis Ribeiro (1997); Soboll (1998); Citadini (1998) e Sanchez (2003).

2. Neste trabalho assumimos que os participantes do governo têm interesse em controlar a Administração Pública. Mesmo quando eles próprios são corruptos, precisam controlar a burocracia, já que normalmente trabalham num ambiente de recursos escassos. Trataremos disso mais adiante.

3. Existe uma extensa literatura sobre este assunto, entre outros: Kliksberg (1984); Lima Junior, (1998); Martins (1999), e Resende (2002). 
incidiam sobre o problema do controle sobre a burocracia. Deter-nos-emos nas propostas derivadas do neo-institucionalismo econômico, cujas ferramentas analíticas, principalmente a Teoria de Agência, serão de especial importância para o andamento do trabalho.

A Teoria de Agência é um importante instrumento para entender as relações contratuais delegativas, onde incentivos e controles são fundamentais, caso típico das burocracias públicas. Originária da microeconomia, tal teoria tem como fundamento um determinado modelo comportamental dos agentes que precisa ser bem definido para não perder poder analítico. Desta forma, primeiramente, definiremos o modelo que será utilizado no trabalho e que ajudará a entender melhor os fundamentos da Teoria da Agência. Em seguida, descreveremos a Teoria da Agência e um dos casos emblemáticos em que nos defrontamos, no âmbito do sistema administrativo estatal, com os problemas levantados pela teoria, isto é, nas relações entre governo e burocracia. Isto nos levará a uma redefinição do conceito e a apresentação dos parâmetros necessários à organização de um sistema de Controle Interno que minimize as possibilidades de comportamentos corruptos.

A administração pública burocrática foi inicialmente adotada no final do século XIX por alguns países da Europa em substituição à administração patrimonialista, sistema característico das monarquias absolutas. Com a emergência do capitalismo, tornou-se necessário desenvolver um tipo de administração que contemplasse uma distinção clara entre o público e o privado. Começa assim a tomar forma a administração burocrática moderna, baseada na estrutura piramidal de poder, no princípio hierárquico de comando, nas rotinas rígidas, no controle dos processos administrativos e com administradores profissionais especialmente recrutados, que respondiam aos políticos.

A ascensão dessa forma de organização foi estudada e compreendida por diversos autores, principalmente por 
Max Weber, autor que reconheceu a inevitabilidade do modelo de organização burocrático. Em sua perspectiva, a modernização social implicava no aparecimento de instituições fortes, baseadas na centralização, na disciplina normativa e no caráter impessoal da ação dos membros, condições estas que só o tipo de organização burocrática poderia oferecer (Bendix, 1986, p. 25).

No entanto, embora Weber tenha estudado a organização burocrática (seus atributos morfológicos) sua principal preocupação foi quanto ao advento do fenômeno burocrático (burocracia enquanto forma de dominação racional/ legal), pois a burocracia estatal constituiu-se num tipo de poder derivado principalmente da concentração da informação e da capacidade organizacional. Por este motivo, apesar de considerar a burocracia uma forma de organização adequada às necessidades advindas da modernização capitalista, Weber atentou para a necessidade de controlar esse poder. $\mathrm{O}$ surgimento do Estado burocrático, para o autor, poderia levar a uma renúncia das responsabilidades por parte da liderança política e a usurpação das funções políticas pelos administradores, ameaçando a legitimidade do Estado democrático (Weber, 1979).

O modelo de organização burocrático respondeu com bastante eficácia às demandas administrativas do período anterior à II Guerra Mundial, dada a relativa baixa complexidade das administrações públicas. No entanto, esse contexto mudou no período imediatamente posterior à II Guerra. Sob o predomínio do paradigma keynesiano de Estado, caracterizado por um rápido crescimento econômico, as estruturas estatais começam a adquirir uma maior complexidade dos sistemas administrativos e um crescimento das burocracias estatais. Uma das conseqüências deste processo de mudanças foi a ampliação do grau de autonomia das organizações públicas sem a correspondente regulação política. 
O problema do controle sobre a burocracia tornou-se crucial, principalmente a partir da década de 1970, com a chamada Crise Estrutural (Evans, 1993, p.108), que atingiu de maneira particularmente intensa os Estados de modelo keynesiano, tanto os de Bem-Estar Social quanto os desenvolvimentistas. A constante demanda em quantidade e diversidade de tarefas levou ao crescimento horizontal e vertical das burocracias, criando pirâmides administrativas que tornaram por enfraquecer os clássicos mecanismos de controle e coordenação. Esse contexto histórico possibilitou a emergência de diversas escolas de pensamento preocupadas em dar respostas a esses problemas, entre elas, a Teoria da Escolha Pública (Public Choice), a Nova Gestão Pública (New Public Management) e diversas correntes neo-institucionalistas. É nestas últimas que nos deteremos.

\section{O Neo-institucionalismo}

148 A partir da década de 1980, autores que aplicam instrumentos da análise econômica para a compreensão das instituições político/administrativas, começaram a apontar diferentes soluções aos problemas administrativos em geral e burocráticos em particular. Trata-se de correntes chamadas neo-institucionalistas, que desenvolveram importantes instrumentos analíticos para tratar as transações sociais em situações de mercado e em contextos organizacionais e hierárquicos, tanto públicos como privados ${ }^{4}$.

Dentre essa gama de correntes, o neo-institucionalismo econômico adota um paradigma contratualista para examinar as instituições e a interação entre indivíduos (ou gru-

\footnotetext{
4. Ver Hall \& Taylor, 2003.

5. Uma das mais importantes é a Teoria dos Custos de Transação. Esta teoria tem diferentes linhas que respondem as seguintes preocupações: (a) as formas de organização, especialmente a firma (Coase, Willimson, Simon); (b) a história econômica e a mudança institucional (North, Ouchi); e (c) as interações entre titular/agente (Arámbula \& Alvarez, 1993).
} 
po de indivíduos), no qual as transações são representadas como contratos entre duas partes ${ }^{5}$. O importante a enfatizar é que representantes desta corrente mudam metodologicamente o pressuposto do comportamento maximizador dos agentes da escola neoclássica e adota o conceito de racionalidade limitada, como veremos mais adiante com maior precisão. Isto significa que os agentes possuem informação incompleta e atuam em um ambiente de incertezas. Isto é, podem ter altos custos para obter informações relevantes sobre as transações que realizam. Neste marco, as instituições são consideradas como elementos centrais do contexto estratégico dos atores, pois impõem os limites e definem o leque de estratégias que podem adotar quando perseguem seus objetivos (Przeworski, 1996; Prats, 1998).

Uma importante ferramenta analítica utilizada pelo neo-institucionalismo econômico é a Teoria de Agência. Neste trabalho, utilizamos esta teoria para entender os problemas derivados da necessidade de controles sobre a Administração Pública. O que se procura é entender se o Estado pode criar e fortalecer sua "capacidade institucional”, entendida como a capacidade estatal de estabelecer, garantir e fortalecer mecanismos legais e administrativos de planejamento, coordenação, controle e coerção. Isto implica, entre outros aspectos, capacidade para elaborar normas e procedimentos de controles eficazes que permitam coibir ações prejudiciais ao interesse público por parte dos agentes do Estado (Costa, 1998, p. 17).

\section{O Modelo}

A Teoria de Agência é um importante instrumento para analisar os conflitos e os processos de tomada de decisão em ambientes hierárquicos, onde existe delegação de poder por meio de um contrato. Como já dissemos, tal teoria tem como fundamento um determinado modelo comportamental que precisa ser bem definido para não perder 
poder analítico. A seguir, será apresentado o modelo adotado neste trabalho. O objetivo é tentar desfazer a confusão que ocasiona o uso do homem econômico - construção analítica da economia neoclássica - como modelo comportamental nos estudos sobre burocracia. Partiremos do conceito de homem econômico, como elaborado pela teoria neoclássica, para mostrar o desenvolvimento do conceito que nos levará a um modelo de interpretação mais adequado para o estudo de organizações hierárquicas, o chamado homem contratual, desenvolvido por Oliver Williamson (1989), que nos ajudará a entender melhor os fundamentos da Teoria da Agência e o problema do controle.

O fundamental na corrente neo-institucional econômica, que parte da economia neoclássica, foi a ampliação do pressuposto do comportamento econômico racional aos políticos e burocratas. Em outras palavras, argumenta que é necessário entender a política como um processo

150 de trocas. Portanto, os agentes dessas trocas - os políticos e burocratas - devem ser analisados como detentores de um comportamento utilitário semelhante ao que teriam se atuassem na esfera econômica. Segundo a Teoria da Escolha Pública, a incorporação dessa premissa comportamental (auto-interesse) como explicativa do processo político, leva a argumentar que não se pode esperar que a escolha dos agentes públicos se identifique com a busca do bem comum (cf. Buchanan, 1985).

No entanto, o modelo comportamental dos agentes econômicos utilizado nas correntes do neo-insitucionalismo econômico não é exatamente o mesmo daquele utilizado pela economia neoclássica. Nesta, é da maior relevância a noção de comportamento maximizador dos agentes (homem econômico), cujo auto-interesse e a busca incessante de lucros constituem a força motriz dos mercados. O resultado desse comportamento utilitário dos agentes no processo de trocas, num ambiente de concorrência perfeita, seria o equi- 
líbrio do sistema econômico e a eficiência geral. Porém, é necessário realizar algumas adaptações ao modelo comportamental para torná-lo mais adequado para entender as relações entre agentes em ambientes hierárquicos, como é o caso de estudos do controle sobre a burocracia. A importância de nos determos nessa adaptação do conceito reside no fato de que isto trará conseqüências lógicas que possibilitará uma melhor compreensão dos fundamentos da Teoria de Agência.

Tentemos entender o conceito de homem econômico. $\mathrm{O}$ homem econômico como formulado pelos economistas neoclássicos é uma construção ideal, um conceito que descreve um agente "perfeitamente racional e onisciente que, ao tomar uma decisão, conhece todas as alternativas de forma que pode escolher com precisão e assim maximizar os resultados de sua decisão. Ele conhece todos os meios que, em cada situação de fato, o levam a atingir seus objetivos" (Fonseca, 1989, p. 160). O homem econômico é um agente dotado de preferências completas e bem ordenadas, amplo acesso à informação e poderes de processamento de informações irrestritos. Estas condições permitem ao agente realizar todos os cálculos necessários para escolher a ação que satisfaz suas preferências melhor do que qualquer alternativa. $O$ agente é racional, no sentido de que ele maximiza de modo consciente uma função objetiva (Simon, 1988, p. 84).

O homem econômico na teoria econômica é visto como um modelo simplificado do comportamento humano que permite lidar com situações onde se considera apenas a variável econômica na determinação do comportamento. Ou seja, é uma abstração idealizada para a análise de situações de troca em mercados competitivos onde agentes atomizados respondem aos sinais de preço relevantes e estabelecem relações horizontais e simétricas entre si (Fonseca, 1989, p. 162). Isto significa que o homem econômico foi criado para atuar em um ambiente preciso. 
A formulação do conceito de homem econômico nesses termos nos leva a um problema quando o assunto a tratar é o controle do poder do Estado. Observemos como Fonseca descreve o comportamento do homem econômico:

"Os agentes buscam seu auto-interesse com total idoneidade, ou seja, 'jogam limpo' todo o tempo, sem violar as 'regras do jogo' - sem infringir a lei, roubar, mentir, dissimular, trapacear ou explorar em benefício próprio ambigüidades contratuais que surjam ao longo das transações." (Fonseca 1989, p.163.)

Desta forma, segundo a interpretação de Fonseca, esse conceito acaba por se tornar inadequado para o estudo dos controles. Tentemos entender por que o homem econômico "joga limpo". O homem econômico é uma construção formulada para um mercado ideal, e nesta construção ideal não se leva em conta as imperfeições dos mercados reais. O homem econômico "joga limpo" porque, segundo sua definição, todos os agentes envolvidos numa transação, e que atuam num ambiente onde as relações são horizontais e simétricas (mercado ideal) possuem informação completa. Nessa construção ideal, o dolo é uma impossibilidade lógica. É por possuir informação completa que nas transações entre homens econômicos "as posições iniciais se relevam de maneira franca e aberta, as declarações do estado do mundo serão precisas, e a execução esta regida pelo juramento ou a regra [...]. Dado que não há surpresas posteriores, pode-se argumentar que existe uma condição de busca simples do interesse próprio" (Williamson, 1989, p. 58).

Se o dolo não é possível no modelo por conta do ambiente - o mercado ideal, onde todos os agentes têm informação completa - a tentativa de incorporar um comportamento que permita problematizar o controle sobre os agentes do Estado (pela incorporação ao modelo das assi- 
metrias informacionais) traria mudanças tão grandes ao modelo que perderia sentido chamar este agente de homem econômico. Como veremos a seguir, uma das conseqüências dessa mudança será o estabelecimento de um outro modelo, embora se mantendo a premissa básica da busca do autointeresse.

Diferentemente do mercado ideal, os agentes no mercado real atuam muitas vezes em ambientes hierarquizados. Este é o caso das firmas e das administrações públicas. Nos ambientes hierárquicos, os agentes deparam-se com determinadas limitações para fazer escolhas, ou seja, não dispõem de tempo ilimitado para tomar decisões, se defrontam com prioridades simultâneas e, principalmente, atuam num ambiente de incertezas. Tudo isso faz com que a informação disponível aos agentes seja incompleta (Simon, 1988, p. 95).

O problema é dado pelo fato desse ambiente levar a uma mudança em um dos atributos mais importantes do modelo, qual seja, o da racionalidade plena. Isto é, o agente, nesse modelo, por atuar em um ambiente de incertezas e de informação incompleta, teria limitada sua capacidade de enumerar todas as alternativas para realizar suas escolhas. É para se adequar a um ambiente hierárquico que se confere ao modelo a condição de racionalidade limitada (bounded rationality). Ou seja, é a inclusão da assimetria de informação, por meio da verticalidade das relações neste ambiente que representam as imperfeições do mercado, que acaba por redefinir o conceito de homem econômico.

A racionalidade limitada é a principal característica do homem administrativo, um conceito desenvolvido por Herbert Simon no trabalho Administrative Behavior (1947). Simon supõe que os agentes são intencionalmente racionais, mas apenas em forma limitada. Observe-se a referência simultânea à racionalidade procurada e por sua vez limitada, por causa da ausência de um sistema completo de informações. 
Isto significa que a capacidade do agente em colher, armazenar e processar informações relevantes para a tomada de decisões é restringida externamente.

Segundo Simon, o comportamento real não alcança racionalidade objetiva, pelo menos em três aspectos: a) "A racionalidade requer um conhecimento completo e antecipado das conseqüências resultantes de cada opção. Na prática, o conhecimento dessas conseqüências é sempre fragmentário."; b) "Considerando que essas conseqüências pertencem ao futuro, a imaginação deve suprir a falta de experiência em atribuir-lhes valores, embora estes só possam ser antecipados de maneira imperfeita."; e c) "A racionalidade supõe uma opção entre todos os possíveis comportamentos alternativos. No comportamento real, apenas uma fração de todas estas possíveis alternativas é levada em consideração." (Simon, 1988, p. 95.) Nesse cenário as escolhas dos agentes serão intencionalmente racionais, mas essas esco154 lhas poderão levar a resultados subótimos devido aos fatores acima descritos. Portanto, tratar as relações entre os agentes em ambientes hierárquicos por meio do homem econômico com racionalidade limitada é um problema de conceituação. É conveniente deixar isto claro, pois o fato de existir informação assimétrica traz conseqüências importantes que desvirtua o conceito de homem econômico como construído pelos economistas neoclássicos. Isso tem conseqüências importantes na formulação de um novo modelo.

O homem administrativo, de Simon, compartilha com o homem econômico a razão instrumental e o comportamento auto-interessado. A diferença, basicamente, está nas condições em que o agente toma suas decisões.

A importância de estabelecer o tipo de ambiente onde os agentes atuam não pode ser desprezada. Neste sentido, Williamson (1989) foi além de Simon ao tirar as conseqüências lógicas do modelo derivadas desse ambiente. Segundo o autor, a ausência de informação completa permite que 
os agentes busquem o auto-interesse explorando as assimetrias de informação, ou seja, permite a inclusão no modelo do chamado comportamento oportunista. Esta construção analítica, isto é, de um agente que persegue o auto-interesse, possuidor de uma racionalidade limitada e com propensão a comportamentos oportunistas, é o que Oliver Williamson denominou de o homem contratual ${ }^{6}$.

Williamson parte da premissa de que o homem contratual, assim como o homem econômico, tem como objetivo final maximizar o retorno de suas ações. No entanto, a competência para lograr essa maximização no homem contratual é limitada. Embora os dois conceitos disponham de um sistema completo e consistente de preferências, o homem econômico tem toda a informação necessária e, portanto, pode escolher sempre entre alternativas que possibilitariam a maximização dos seus interesses. Não existe limite na complexidade dos cálculos que pode realizar para determinar qual alternativa é a melhor. Diferentemente, o homem contratual tem restringida sua capacidade de colher, armazenar e processar informações relevantes para a tomada de decisões. Consciente desta limitação, ao invés de maximizar, como faz o homem econômico, ele se contenta em satisfazer como faz o homem administrativo de Simon (1988, p. 63).

O segundo pressuposto do homem contratual é a propensão ao oportunismo. O oportunismo se refere ao uso de informações incompletas ou distorcidas em beneficio próprio. É um comportamento que objetiva conseguir vantagens criando ou explorando assimetrias de informação. Este tipo de comportamento tem importantes implicações teóricas. A presença do oportunismo como ameaça constante leva à busca de inúmeras garantias contratuais como

6. Williamson (1985. p. 57) entende o oportunismo como a busca do interesse próprio com dolo, no sentido de uma ação que prejudique a outra parte do contrato, o que não significa necessariamente quebra de contrato. 
forma de se precaver ante a possibilidade desse tipo de comportamento. Em outras palavras, com o homem contratual deixa de valer o pressuposto de que um sistema, político ou econômico, goza de uma oferta ilimitada de confiabilidade pessoal (Fonseca, 1989, p. 64). Como a propensão ao oportunismo é uma ameaça latente, devem-se criar inúmeras salvaguardas ex ante e ex post o contrato para prevenir esse comportamento, que tem como conseqüência o aumento dos chamados custos de transação ${ }^{7}$.

Resumindo, o aspecto fundamental sob o qual é construído conceitualmente o homem contratual é o das assimetrias informacionais dadas pelo ambiente hierárquico. A presença de informação imperfeita restringe a capacidade dos agentes agirem com racionalidade plena. E esta condição tem duas conseqüências. A primeira é que, diferentemente do modelo do homem econômico da economia neoclássica, que tem entre suas mais proeminentes características o de ter como objetivo sempre maximizar seus ganhos, o homem contratual se contentará em apenas satisfazer-se. E em segundo lugar, a assimetria informacional entre os agentes

7. Um dos principais efeitos da ameaça latente do comportamento oportunista dos agentes é o aumento dos custos de transação. Utilizado desde as primeiras décadas do século XX, o conceito de transação é essencial no estudo das instituições econômicas vistas como redes de contratos individuais que buscam maximizar o próprio interesse. Foi em 1937 que Ronald Coase desenvolveu os princípios da teoria dos custos de transação com a publicação de The Nature of the Firm (1937). O trabalho de Coase é centrado na análise de duas formas organizacionais concorrentes, firma e mercado, na coordenação dos agentes econômicos. Ou seja, estuda a organização econômica em termos institucionais comparados (Williamson, 1989, p. 23). A questão central é entender a incidência das instituições na formação dos custos de transação. Isto é, os custos de desenhar, negociar, prever salvaguardas contratuais, assim como os de manter mecanismos de monitoramento e controle. Esses custos serão maiores ou menores dependendo do ambiente institucional em que ocorre a transação. Mecanismos de controle frágeis darão lugar a uma margem maior de comportamentos oportunistas dos agentes envolvidos. Da mesma forma acontecerá ante a existência de regras vagas nas prevenções contratuais. Como observou Douglass North (1993, p. 53) "só se obtêm os resultados neoclássicos de mercados eficientes quando não há custos de transação. Quando estes são consideráveis, as instituições passam a adquirir importância”. 
permite o aparecimento do comportamento oportunista. E é o oportunismo que obriga a construção de inúmeras garantias pré e pós contratuais, aumentando os custos de transação numa sociedade ${ }^{8}$.

\section{A Teoria de Agência}

A compreensão do modelo do homem contratual é uma boa introdução para o estudo da Teoria de Agência. Segundo esta teoria existe uma relação titular/agente quando um indivíduo, um grupo ou uma organização, que tem um poder específico, delega, por meio de um contrato, responsabilidades a um outro indivíduo, grupo ou organização. Neste sentido, uma organização é uma rede diferenciada de relações específicas e hierárquicas, como por exemplo, entre proprietário e diretor, entre diretor e gerente e entre gerente e funcionário. Nestas relações existem contratos, escritos ou não, rígidos ou flexíveis, que determinam a atuação de cada agente e a probabilidade desta atuação atender à expectativa do titular, que delega responsabilidades. O problema neste tipo de relacionamento reside na assimetria de informação, ou seja, no fato de duas partes que se relacionam não deterem a mesma informação, colocando uma das partes - quem delega responsabilidades, o titular - em desvantagem no relacionamento com o outro, o agente (chamaremos a isto de o problema de delegação). É importante observar que os problemas trazidos pela Teoria de Agência são mais compreendidos quando os pressupostos comportamentais são os do homem contratual, que tende a aproveitar as assimetrias de informação existente na relação titular/agente para obter vantagens.

8. Williamson (1985, p. 73) adverte: "No intento decir que los individuos se inclinen de forma continua, o incluso, de lleno, por el oportunismo. Solo afirmo que algunos individuos son oportunistas a veces y que la confiabilidad diferencial es raras veces transparente ex ante. En consequencia, se hacen esfuerzos de selección ex ante y se crean salvaguardas ex post." 
No caso das organizações burocráticas estatais, a teoria nos permite pressupor uma cadeia de relações titular/agente. $\mathrm{O}$ agente em um contrato pode ser o titular em outro contrato, pois as organizações não existem isoladamente, mas revelam sua existência nos seus relacionamentos, em que a organização aparece ora como titular e ora como agente. A satisfação do titular depende da atuação do agente, portanto, o titular deve assegurar-se de que a atuação do agente será aquela que satisfaça seu objetivo. Como o agente pode ter comportamentos oportunistas, o titular deverá fazer esforços de seleção e formular um contrato com esquemas de incentivos e de controles eficientes. Os incentivos podem abranger estímulos positivos (prêmios) ou negativos, tais como penalidades contratuais. Os incentivos positivos são muito comuns nas relações privadas e visam criar uma situação onde o interesse do agente seja coincidente com o do titular. Por exemplo, é normal que vendedores sejam remunerados, além de um salário fixo, com comissão por vendas. Assim, mesmo tendo um ganho fixo para garantir certos períodos de vendas fracas, o vendedor se esforçará por toda venda possível, visando ganhar comissão. A comissão faz que, pelo menos em alguns aspectos, o interesse do agente seja coincidente com o do titular.

Assim, o problema de delegação, de uma relação titular/ agente, possui as seguintes características: a) o agente dispõe de vários comportamentos possíveis de serem adotados; b) sua ação afeta o bem-estar das duas partes; e, c) as ações do agente dificilmente são observáveis pelo titular (assimetria de informação).

Devido a latente propensão do agente ao oportunismo, haverá basicamente dois tipos de problemas: a seleção adversa e o risco moral. A seleção adversa ocorre quando o esquema de incentivos de um contrato não está bem formulado, fato que pode levar ao agente a escolher o inverso daquilo que deseja o titular. O risco moral surge dos problemas subjacentes à 
criação dos contratos. Trata-se da possibilidade de o agente, depois de firmado o contrato, valer-se de brechas contratuais para agir em interesse próprio, impondo um prejuízo ao titular. Como observa Melo (1996, p. 71) "seleção adversa resulta da não observabilidade da informação, valores e objetivos que marcam as decisões do agente. Enquanto o conceito de risco moral resulta da não observabilidade do comportamento do agente numa situação pós contratual".

O sucesso numa relação titular/agente deve levar em conta os seguintes aspectos: a) A feitura do contrato deve prever as diversas alternativas de comportamento possíveis do agente; b) O esquema de incentivos deve ser modelado para que o agente tenha interesse em atingir os objetivos do titular; e, c) no caso do titular não poder observar continuamente o desempenho do agente e/ou não saber julgá-lo, deve estabelecer um sistema de seleção e de monitoramento e controle confiável.

Existem três casos emblemáticos em que nos defrontamos com problemas de agência. $\mathrm{O}$ primeiro ocorre no âmbito do sistema político, onde os políticos (agente, neste caso) recebem uma delegação dos cidadãos (titular) para agir em seu nome. O segundo refere-se à relação entre o Estado (titular) e empresários (agente). E o terceiro ocorre no âmbito da Administração Pública, onde o agente representa o empregado contratado pelo governo (titular) para realizar uma tarefa especificada (Przeworski, 1996, p. 23).

Neste trabalho daremos ênfase a problemas derivados do terceiro caso, que se refere à relação entre governantes e burocracia, ou seja, à dificuldade dos governantes em controlar os funcionários do Estado, possuidores da informação técnica e organizacional e de especialização. Nesta situação os governantes podem se deparar com problemas de seleção adversa e risco moral quando a burocracia, que detêm conhecimento técnico e organizacional, pode utilizar determinadas informações para obter vantagens que vão contra o interesse 
dos governantes. Em outras palavras, havendo delegação, o burocrata pode optar por um comportamento oportunista em beneficio próprio e não cumprir com o acordo estabelecido. A questão fundamental, como a levantada por Arrow (1963), quando desenvolveu os problemas derivados das "falhas do governo", é a relativa aos custos de obtenção de informaç̃es, questão que é crucial ao processo decisório ao controle.

Do ponto de vista da Teoria de Agência, o problema do controle sobre a burocracia estatal dependerá da forma de como são construídos, em cada sociedade, arranjos institucionais que limitem e constranjam os possíveis comportamentos oportunistas dos agentes, pois são as instituições que organizam essas relações.

\section{Controle Interno: Uma redefinição}

A partir da Teoria de Agência podemos entender melhor o 160 problema do controle sobre a burocracia. Uma organização pública pode ser considerada como uma rede de relações específicas e hierárquicas, onde cada funcionário é ora o titular, ora o agente, sendo a cúpula dirigente o titular último dentro da organização. Para controlar essa estrutura, visando manter as atividades dentro da lei, segundo as necessidades do serviço e as exigências técnicas e econômicas de sua realização, existem os controles administrativos, que são exercidos pelo corpo coletivo da organização por meio do poder hierárquico, que estabelece uma relação de subordinação entre os agentes públicos.

"A submissão hierárquica retira do inferior a atuação política, isto é, despe o subordinado da ação de comando, permitindo-lhe tão-somente agir no estrito âmbito de suas atribuições específicas. Ao chefe do órgão executivo é que incumbe tomar as resoluções políticas, no sentido da escolha do objeto, dos meios e da oportunidade mais 
conveniente à consecução dos fins governamentais."

(Meirelles, 2000, p. 113.)

Existe uma questão que diferencia a cúpula política, que detém o comando, do restante da organização: é a questão da responsabilidade. Como já dissemos, embora todos tenham responsabilidade administrativa, apenas a cúpula tem responsabilidade política. Em conseqüência, é ela a responsável pela prestação de contas da organização aos controles horizontais e aos controles sociais.

A questão da responsabilidade é de vital importância num sistema democrático, o que nos faz enfatizar a relevância do controle dos políticos sobre a burocracia. Levando em conta a diferenciação entre a cúpula do restante da organização burocrática, podemos redefinir o conceito de Controle Interno como o controle da cúpula política (titular) sobre a burocracia (agente) ${ }^{9}$. Assim, com essa definição, diferenciamos os Controles Internos dos controles administrativos, que são intrínsecos à própria organização e que fazem parte da dinâmica da estrutura hierárquica. Essa definição leva em conta um sistema de Controle Interno exercido preferentemente pela própria cúpula sobre a burocracia e não um controle por meio da burocracia.

Para além do fato de que o agente político tem o "dever" (a responsabilidade) de controlar a burocracia, o modelo estabelece que a cúpula política, que detém o poder, tem interesse em controlar seus subordinados. Controlar, para um governante, é saber o que acontece na Administração Pública. Mesmo quando ele próprio é corrupto precisa controlar a burocracia, já que normalmente trabalha num ambiente de recursos escassos. Da mesma forma, a cúpula

9. Para efeito de maior compreensão e por falta de um nome melhor, passaremos a chamar os controles exercidos diretamente pela cúpula dirigente de Controle Interno (com maiúsculas) de forma a diferenciá-lo dos controles internos (em minúsculas) puramente administrativos. 
governante precisa responder aos eleitores para manter-se no poder. Portanto, para implementar suas políticas não pode prescindir dos recursos que seriam evadidos pela ineficiência e pela corrupção da burocracia.

No entanto, mesmo ante essa necessidade, o controle sobre a burocracia é de difícil consecução. Definido o problema de controle sobre a burocracia como um problema de delegação, a teoria nos leva a identificar três questões básicas que precisam de resposta para estabelecer um Controle Interno, a saber: a) a necessidade de diminuir os custos de se obter informação; b) a necessidade de obter ganhos em expertise (para saber avaliar as escolhas do agente); e, c) a formulação de uma arquitetura institucional de forma a existir coincidência de interesses entre os agentes do controle e o titular, para evitar o problema do "controle sobre o controlador".

Em primeiro lugar, há a necessidade imperativa de diminuir os custos de se obter informações. Neste sentido, argumenta Przeworski:

"Os agentes dispõem de informações que os titulares não observam diretamente: conhecem suas próprias preferências, dispõem de uma informação privilegiada sobre suas capacidades e têm a chance de perceber alguns estados possíveis do mundo que os titulares não podem perceber. Estes, por sua vez, podem ser capazes de observar, sem, sem muito esforço, certos comportamentos do agente ou inferir suas ações a partir do resultado ou ainda podem decidir arcar com os custos de monitorar tais atos. (Przeworski, 1996, p. 22.)

A capacidade de observar sem muito esforço o comportamento do agente é possível nas pequenas organizações, onde o proprietário pode observar continuamente o trabalho dos funcionários e julgar a qualidade do desempenho, pois normalmente é um especialista no seu ramo de negó- 
cio. Entretanto, o problema é crucial nas grandes organizações onde o titular não pode observar continuamente o trabalho de seus funcionários, nem pode julgar com exatidão a qualidade do desempenho destes, pois normalmente não é um especialista em cada ramo do negócio (não pode, portanto, avaliar todas as escolhas do agente). Assim, precisa criar mecanismos de controle que lhe informem sobre o desempenho do agente.

Os mecanismos de obtenção de informações para o controle do titular sobre o agente são basicamente dois: mecanismos de patrulha de polícia e mecanismos de alarme de incêndio ${ }^{10}$. O primeiro é constituído por informações produzidas nos tradicionais controles administrativos. Consiste na verificação do cumprimento das regras e procedimentos e o respectivo controle da conformidade dos atos da administração. O segundo tipo de mecanismo refere-se à produção de informação para o controle através da participação da sociedade organizada.

Estes últimos baseiam-se na comparação entre as burocracias públicas e as burocracias de empresas privadas. Ambas oferecem produtos ou serviços ao público. No caso de uma firma, é o nível das demandas dos consumidores pelos serviços ou produtos oferecidos que irá gerar lucros ou perdas aos proprietários. Desta forma, estes obtêm informação gratuita do público a respeito do desempenho da empresa e podem estabelecer comparações com o desempenho de outras empresas similares. Diferentemente, um órgão público não tem esses parâmetros de comparação, o que dificulta aos seus dirigentes a avaliação da qualidade dos serviços prestados. Não obstante, é o público que utiliza os serviços, quem está melhor informado sobre seu desempenho. Assim, os políticos eleitos (e a burocracia dirigente) poderiam se beneficiar das informações produzidas pelo 
público interessado. Mas, neste caso, é necessário implementar mecanismos institucionais que possibilitem a participação social (Przeworski, 1998).

Segundo Adam Przeworski, um sistema de controle baseado em mecanismos de alarme de incêndio teria a vantagem de permitir obter informações a um custo mais baixo que por meio de uma supervisão tipo patrulha de policia. Entretanto, mesmo levando em conta essa vantagem, a participação pública não elimina a necessidade de controle baseado em mecanismos de patrulha de polícia.

Com efeito, no âmbito da Administração Pública o tamanho e a complexidade de funções da máquina estatal fazem com que o problema dos custos de obtenção de informação seja crítico. Sem minimizar este problema não haverá a possibilidade de construção de um sistema de Controle Interno como definido acima.

Em segundo lugar, existe a necessidade de se adquirir expertise, que consiste em conhecimento tanto técnico quanto do funcionamento da máquina administrativa. A Administração Pública, para registro e implementação dos seus atos, controle da conduta dos agentes e solução de controvérsias dos administrados, utiliza-se de diversos procedimentos que recebem a denominação comum de processo administrativo. Estes processos se materializam por meio de instruções, circulares, avisos, portarias, ordens de serviço, ofícios ou despachos que respondem a regras que determinam o tempo, o lugar e a comunicação dos atos desenvolvidos (Meirelles, 2000, p. 173-5). Entender esse funcionamento (os meandros) da máquina pública é o que chamamos de expertise organizacional. Por outro lado, chamamos de expertise técnica o conhecimento extenso de uma tarefa específica, adquirido através de treinamento, leitura e experiência. É esse conhecimento que oferece subsídios para avaliar as escolhas do agente, comparar e decidir. 
E em terceiro lugar, existe a dificuldade organizacional na criação do Controle Interno. Segundo a Teoria de Agência, a questão da arquitetura institucional também é de especial importância, pois a principal característica do Controle Interno proposto é que deve estar organizado de forma a não reproduzir os problemas de delegação que existem dentro de uma estrutura burocrática. O que levaria a enfrentar o problema de como controlar o controlador.

A cúpula dirigente de uma organização é o titular que delega funções aos diretores. Estes, por sua vez, delegam aos gerentes e assim por diante. Se os Controles Internos estão situados em algum ponto dentro dessa estrutura hierárquica, se reproduzirá o problema de delegação entre o titular e o agente. Uma solução seria que os Controles Internos estivessem ligados diretamente à cúpula dirigente.

Idealmente, os integrantes do Controle Interno deveriam fazer parte da própria cúpula política. Ante a impossibilidade prática desta situação, a questão levantada pela teoria é de construir um esquema de incentivos que garanta a coincidência de interesses entre os funcionários do controle e os interesses da cúpula política.

O problema de qualquer modelo é a sua aplicabilidade, isto é, a forma como se pode traduzir um problema teórico em arranjos institucionais e mecanismos administrativos. No âmbito da Administração Pública os problemas expostos nos itens acima seriam de difícil solução sem o aparecimento da nova Tecnologia de Informação e Comunicação (TIC). Com efeito, nos dias de hoje já é plenamente aceito que a TIC tem potencial para deixar de ser apenas uma ferramenta de apoio na administração pública e passar a ser utilizada como instrumento estratégico dos governos, uma forte aliada dos administradores devido a sua crescente capacidade de captar e concentrar informação e facilitar o desenvolvimento de reformas administrativas que limitem o elemento não previsível do exercício do poder por meio 
da criação de arranjos institucionais que atuem como constrangedores da conduta dos agentes públicos ${ }^{11}$.

Finalmente, os critérios de análise dos problemas administrativos de controle, desenvolvidos neste trabalho a partir da Teoria de Agência, podem servir de instrumento para guiar, compreender e avaliar reformas na Administração Pública no sentido de aumentar a capacidade de controle.

\section{Conclusão}

Como já vimos, segundo Weber, numa democracia, os políticos eleitos são detentores de legitimidade e responsabilidade política. Cabe a eles, por meio dos partidos, a formulação de programas políticos a serem referendados pelos eleitores. Com o advento da burocracia como forma de dominação racional/legal Weber percebeu o risco de a burocracia estatal avançar em suas atribuições e passar a formular políticas, dado que dispõe de conhecimento técnico necessário para tanto. Por mais que a formulação de políticas necessite de conhecimento técnico, a burocracia não é apta a tomar esta ou aquela decisão, pois lhe falta legitimidade. É uma questão de accountability política, já que os burocratas não são eleitos. Em conseqüência, torna-se imperativo num regime democrático, o controle dos políticos sobre as ações da burocracia, pois pode haver o falseamento das metas estabelecidas. E um exemplo disso é dado pelo problema da corrupção burocrática.

No entanto, a construção de mecanismos que tornem viável esse controle sempre representou problemas, às vezes intransponíveis, para os governantes e administradores. Isto se deve ao fato da burocracia constituir um grupo especializado e possuir alta capacidade organizacional. Ela detém certa quantidade e qualidade de informação que a coloca em posição de vantagem em relação aos agentes políticos.

11. Ver Oscar A. Sanchez (2005). 
Para uma melhor compreensão do problema do controle sobre a burocracia, recorremos à Teoria de Agência em busca de ferramentas analíticas. A teoria nos diz que o problema nas relações delegativas reside na assimetria de informação, ou seja, no fato de duas partes que se relacionam não deterem o mesmo conhecimento, colocando uma das partes em desvantagem no relacionamento com o outro. Segundo o modelo, o agente poderá utilizar de forma oportunista essa assimetria de informação para obter vantagens. Desta forma foi estabelecida a dificuldade do controle dos políticos sobre a burocracia como derivada do problema de delegação.

Como se enfrenta o problema de delegação? A satisfação do titular depende da atuação do agente, portanto, o titular deve assegurar-se de que a atuação do agente será aquela que satisfaça seu objetivo. Como o agente pode ter comportamentos oportunistas, então o titular deve realizar um cálculo para decidir se arca com os custos desse controle.

A partir do modelo de comportamento do homem contratual, adotado neste trabalho, assume-se que nas relações contratuais delegativas do setor público os controles são fundamentais, pois, mesmo ante um contrato que tente prever todas as situações possíveis, sem um esquema eficiente de controles, haverá dificuldades no cumprimento do contrato. Nesse sentido, a Teoria de Agência nos permitiu avançar em um aspecto importante, qual seja, a redefinição do conceito de Controle Interno como sendo o controle dos políticos sobre a burocracia, levando em conta que são os políticos que devem prestar contas perante os cidadãos.

A redefinição do conceito nos levou a identificar três problemas básicos a serem enfrentados na implementação de reformas administrativas: a) a necessidade de diminuir os custos de se obter informação; b) a necessidade de obter ganhos em expertise tanto organizacional quanto técnica (para poder avaliar as escolhas do agente); e, c) a necessidade de produzir uma situação em que seja possível a coinci- 
dência de interesses entre o titular e os agentes do controle. Enfrentar esses três problemas nos levará à construção de arranjos institucionais que permitam o controle da cúpula dirigente sobre a burocracia minimizando o problema de delegação. Da mesma forma, nos pode oferecer critérios de análise dos problemas administrativos de controle.

Não é demais enfatizar que quando se isola a relação titular (cúpula política) / agente (burocracia), o que se procura entender são os problemas resultantes deste tipo específico de relações - dado um determinado modelo comportamental. Para além do fato de que o agente político ter o "dever" (a responsabilidade) de controlar a burocracia, esse modelo estabelece que a cúpula política que detém poder tem interesse em controlar seus subordinados. Mesmo quando ele próprio é corrupto precisa controlar a burocracia, já que normalmente trabalha num ambiente de recursos escassos.

No entanto, esta tese de que o governo sempre quer controlar a burocracia não é tão pacífica. Terry Moe (1984), por exemplo, argumenta que quando os governantes esperam permanecer em seus postos, desejam sim controlar a burocracia, de modo a poder utilizá-la para seus próprios fins. Mas, quando os governantes temem perder seus postos, podem defender que a burocracia se torne autônoma em relação ao controle político, de modo que seus sucessores não a utilizem para obter vantagens partidárias.

A argumentação de Moe nos mostra a importância da necessidade de institucionalização (no sentido de permanência no tempo) de Sistemas de Controle Interno, assim como que a informação produzida seja aberta à sociedade civil. Isto nos leva a refletir sobre outra questão importante: o controle sobre os políticos. Embora este trabalho tenha se limitado ao estudo dos controles sobre a burocracia, são necessárias algumas palavras sobre $\mathrm{o}$ assunto.

Uma das principais críticas à abordagem deste trabalho, diz respeito ao fato de que o titular "detém uma esco- 
lha racional e tenta impô-la ou negociá-la com o agente, o que desconsidera a hipótese do estabelecimento de relações espúrias e clientelistas entre ambos" (Falcão Martins, 1999, p, 15). Em outras palavras, de que serve a implementação de tais reformas, como a do modelo de Controle Interno proposto, no caso de haver governos corruptos? Neste sentido, a centralização do poder e da informação pode ser equivalente à perda de valores democráticos e servir como um instrumento organizacional da corrupção.

Poderíamos resumir o problema de agência à seguinte questão: como evitar que o titular seja lesado pelo agente? O estabelecimento de relações espúrias e clientelistas entre ambos significa que se estabelece um conluio para lesar alguém. Assim, na perspectiva da Teoria de Agência, o problema passa a ser outro dentro da cadeia de relações. Nesse caso, a cúpula política (em conluio com a burocracia) deixa de ser o titular e passa a estar na posição de agente dos cidadãos, que estão sendo lesados. Dessa forma, a teoria nos aponta que este agente político necessita de controle, porque, como demonstra o modelo comportamental, ele optará por um comportamento oportunista quando tiver chance. Para isso existem os controles sociais e os controles horizontais do tipo checks and balances. Mesmo assim, existe a necessidade de se entender estas relações - burocracia/ governo e governo/cidadãos - como partes de uma cadeia e que qualquer ausência de controle nesta cadeia de relações se dará em detrimento dos interesses do titular último, o cidadão.

Desta forma, ao adotarmos a perspectiva do problema de agência e tratarmos o sistema de controles como sendo uma cadeia interdependente de relações titular e agente, damos ao problema dos Controles Internos uma dimensão política. Isso nos leva a ver mais claramente a interconexão entre os dois problemas: o weberiano e o madisoniano. $\mathrm{Ou}$ seja, garantir que seja o agente político que tome decisões 
políticas e a necessidade de se garantir arranjos para controlar as ações desses políticos.

Os arranjos de Controles Internos, como início de uma cadeia de controles democráticos, têm um valor intrínseco, que é o controle dos políticos sobre a burocracia. Além disso, uma das principais contribuições do Controle Interno a essa cadeia de controles democráticos refere-se ao fato de que a abertura da informação e o conhecimento contido neles podem ser fundamentais para um funcionamento muito mais eficaz dos controles sociais e dos controles horizontais. Pode permitir a produção de um fluxo contínuo de informações sobre a Administração Pública e sobre as agências burocráticas, criando assim uma memória institucional sobre cada uma delas e garantindo a continuidade do processo de controle (Loureiro, 2001, p.54).

Esse não é um processo simples. Os políticos desejam controlar, mas não desejam ser controlados. Isto é, as informações e o conhecimento produzido pelos Controles Internos podem "parar na cúpula" e assim impedir um fluxo contínuo de informação para a sociedade. Este problema nos remete à importância da transparência como um mecanismo que permita que as informações produzidas pela burocracia fluam não apenas para o governante, mas também para o cidadão. Da mesma forma, nos remete à importância dos mecanismos de alarme de incêndio como uma via de mão dupla. Por um lado, como mecanismo de obtenção de informação para próprio governante. Ou seja, um sistema estruturado e eficiente de Controle Interno deveria levar em conta também esta forma de obtenção de informações de maneira a coordenar as informações produzidas internamente para que seja possível a exploração de suas potencialidades. E por outro lado, as informações produzidas por mecanismos de alarme de incêndio devem ser utilizadas para o controle sobre os próprios governantes. Portanto, nessa relação titular (cidadãos) e agentes (governo) é preciso que 
se garanta a abertura da informação produzida pelos mecanismos de Controle Interno à sociedade.

Para concluir, ao tratarmos o problema dos controles sobre a burocracia sob a perspectiva weberiana, a partir de instrumentos da Teoria de Agência, fazemos com que esta discussão seja feita sob uma análise política. Em outras palavras, o controle como um imperativo democrático.

\section{Marcelo Araújo}

é mestre em Ciência Política pela USP e pesquisador do Cedec

\section{Oscar Adolfo Sanchez}

é doutor em Ciência Política pela USP e pesquisador do Cedec

\section{Referências Biblográficas}

ARÁMBULA, Héctor \& ÁLVAREZ, David. La economía de los costos de transacción. Una explicación alternativa para el estudio de las organizaciones. Revista Gestión y Política Pública. V. II, n. 2. México: CIDE., 1993.

ARROW, Kenneth. Social choice and individual values. New Haven: Yale University Press, 1993.

BEETHAM, David. A Burocracia. Lisboa: Editora Estampa, 1988.

BENDIX, Reinhard. Max Weber: Um perfil intelectual. Brasília: UnB, 1986.

BUCHANAN, James. Limits of liberty. Chicago: Chicago University Press, 1975.

Press, 1980.

Toward a theory of the renk-seeking society. Texas: University

CAMPOS, Anna Maria. Accountability: Quando poderemos traduzi-la para o Português?. Revista de Administração Pública, 24 (2). Rio de Janeiro: FGV, 1990.

COSTA, Valeriano. O novo enfoque do Banco Mundial sobre o Estado; Revista Lua Nova, n. 44. São Paulo: CEDEC, 1998.

CROZIER, Michel. El fenómeno burocrático. Buenos Aires: Amorrortu, 1974. DAHL, Robert. Poliarquia: participação e oposição. São Paulo: Edusp, 1997.

DOWNS, Antony. Inside Bureaucracy. Boston: Little Brown, 1967.

EVANS, Peter. O Estado como problema e solução. Revista Lua Nova, n. 28/29. São Paulo: CEDEC, 1993. 
FALCÃO MARTINS, Humberto. A contratualização como estratégia de reforma. Trabalho apresentado no Congreso Internacional del CLAD sobre la Reforma del Estado y de la Administración Pública, 4 (Oct. 19-22: México), 1999. Disponível: http://www.clad.org.ve/siare/biblo/es_biblo_ l.html

FONSECA, Eduardo G. Comportamento individual: Alternativas ao homem econômico. Revista Novos Estudos. São Paulo. CEBRAP, 1989.

HALL, Peter \& TAYLOR, Rosemary. As Três versões do Neo-Institucionalismo. Revista Lua Nova, n. 58. São Paulo, CEDEC, 2003.

KLIKSBERG, Bernardo. Reforma administrativa en América Latina: Una revisión del marco conceptual. In: La reforma de la administración pública en América Latina. Madrid: Instituto Nacional de Administración Pública, 1984.

LIMA JUNIOR, Olavo Brasil. As reforma da administração pública e cultura política no Brasil: Uma visão geral. Revista do Serviço Público. Ano 49, n. 2. Brasília: ENAP, 1998.

LOUREIRO, Maria Rita. Burocracia e reforma do Estado. Cadernos Adenauer. Ano II, n. 03. São Paulo: Konrad Adenauer, 2001.

MARTINS, Luciano. Estado capitalista e burocracia no Brasil pós-64. São Paulo: Paz e Terra, 1985.

. Reforma da administração pública e cultura política no Brasil: Uma visão geral. Cadernos ENAP, n. 8. Brasília: ENAP, 1999.

McCUBBINS, M. D. \& SCWARTZ, T. Congressional oversight overlooked: police patrol versus fire alarms. American Journal of Political Science, n.28, 1984.

MEIRELLES, Hely Lopes. Direito administrativo brasileiro. São Paulo: Malheiro Editores, 2000.

MELO, Marcus. Governance e reforma do Estado: O paradigma agente x principal. Revista do Serviço Público, Vol. 120. Brasília: ENAP, 1996.

MOE, Terry. The new economics of organization. American Journal of Political Science, 28 (739/777), 1984.

NISKANEN, William. Bureaucracy and representative government. Chicago: University of Chicago Press, 1971.

O'DONNELL, Guillermo. Accountability horizontal e novas poliarquias. Revista Lua Nova, n. 44. São Paulo: CEDEC, 1998.

PISCITELLI, Roberto. O controle interno na administração pública federal brasileira. Brasilia: ESAF, 1998.

PRATS, Joan. Fundamentos para la reforma del Estado en América Latina. Trabalho PNUD, presentado a la Conferencia sobre Nueva Generación de Políticas Públicas, Montevideo, 1995. 
Marcelo Araújo | Oscar Adolfo Sanchez

Administración pública y desarrollo en América Latina.

Un enfoque neoinstitucionalista. Revista del CLAD, n. 11. Caracas: s.n., 1998.

PRZEWORSKI, Adam. Reforma do Estado: responsabilidade política e intervenção econômica. Revista Brasileira de Ciências Sociais, n. 32. São Paulo: ANPOCS, 1996.

. Democracia y representación. Revista del CLAD, Reforma y

Democracia. n. 10. Caracas: s.n., 1998.

RESENDE, Flavio C. O dilema do controle e a falha sequencial nas reformas gerenciais. Revista do Serviço Público, 53/3. Brasília: ENAP, 2002.

SANCHEZ, Oscar. Os controles internos da administração pública. 2005. Doutorado (Tese apresentada no Departamento Ciência Política da USP), 2005.

SIMON, Herbert. El comportamiento administrativo: estudio de los procesos decisorios en la organización administrativa. Buenos Aires: Aguilar, 1988.

SPECK, Bruno. Mensurando a corrupção: Uma revisão de dados provenientes de pesquisas empíricas. In: Os Custos da Corrupção. São Paulo: Konrad Adenauer, 2000.

TULLOCK, Gordon. What is to be done? In: BORCHERDING, T.E. (ed.). Budgets and bureaucrats: The sources of goverment growth. Durham: Duke University Press, 1977.

WEBER, Max. Economia y sociedad: esbozo de sociología comprensiva. México: Fondo de Cultura Económica, 1964.

Ensaios de Sociologia. Rio de Janeiro: Ed. Guanabara, 1979.

WILLIAMSON, Oliver. Las instituciones económicas del capitalismo. México: Fondo de Cultura Económica, 1989. 


\section{PARTE I}

\section{A CORRUPÇÃO E OS CONTROLES INTERNOS DO ESTADO}

MARCELO ARAÚJO E OSCAR ADOLFO SANCHEZ

$\mathrm{O}$ artigo pretende reavaliar a importância dos Controles Internos da Administração Pública a partir de uma interpretação dada pela Teoria de Agência. O texto argumenta que os Controles Internos, definidos como os controles exercidos por uma organização sobre si própria, podem tornar-se os principais controles sobre a burocracia. $\mathrm{O}$ artigo conclui argumentando que os Controles Internos deveriam ser encarados como sendo parte integrante de um sistema de controles político-democráticos.

Palavras-chave: Controles Internos; Teoria de Agência; Burocracia; Homem Contratual; Corrupção.

\section{CORRUPTION AND THE STATE'S INTERNAL CONTROLS}

This article intends to reevaluate the importance of the Internal Controls Systems of the Public Administration from an interpretation given by the Theory of Agency. This text argues that the Internal Controls, defined as the control exerted for an organization on itself, can become the main control on the bureaucracy and that the Internal Controls should be seen as part of a system of politicaldemocratic control.

Keywords: Internal Controls; Theory of Agency; Bureaucracy; Contractual Man; Corruption. 